\title{
Comparative analysis of factors influencing spatial distributions of marine protected areas and territorial use rights for fisheries in Japan
}

\author{
Keiko J. Nomura ${ }^{\mathrm{a}, \mathrm{b}, *}$, David M. Kaplan ${ }^{\mathrm{b}}$, Jennifer Beckensteiner ${ }^{\mathrm{b}}$, Andrew M. Scheld ${ }^{\mathrm{b}}$ \\ a Biology Department, San Diego State University, San Diego, CA, USA \\ ${ }^{\mathrm{b}}$ Department of Fisheries, Virginia Institute of Marine Science, College of William \& Mary, P.O. Box 1346, Gloucester Point, VA 23062, USA
}

\section{A R T I C L E I N F O}

\section{Keywords:}

Marine protected area (MPA)

Territorial use right for fisheries (TURF)

Marine spatial planning (MSP)

Ecosystem-based management (EBM)

\begin{abstract}
A B S T R A C T
As increasingly large extents of the global oceans are being managed through spatial measures, it is important to identify area characteristics underlying network distributions. Studies discerning spatial patterns in marine management have disproportionately focused on global networks. This paper instead considers the single country context of Japan to illuminate within-country drivers of area-based conservation and fishery management. A dataset containing potentially relevant socioeconomic, environmental, and fisheries factors was assembled and used to model prefecture-level counts of marine protected areas (MPAs) and territorial use rights for fisheries (TURFs) throughout Japan's waters. Several factors were found to significantly influence the number of TURFs in a particular area, whereas MPA patterns of use remain largely unexplained. TURFs are frequently noted as more suitable for managing fisheries of low mobility species and our analysis finds greater use of TURFs in areas that rely heavily on benthic catch. The number of trading ports was also found to be positively related to TURF distributions, suggesting economic infrastructure may influence the use of this fisheries management tool. In-line with global analyses, MPA patterns of use were not found to be significantly related to any of the potential explanatory variables after correcting for the number of statistical comparisons that were carried out. Differences in our ability to model the use of TURFs and MPAs may arise due to the narrower objectives associated with the former (e.g., income, employment) in comparison to the often broad and varied goals that motivate use of the latter.
\end{abstract}

\section{Introduction}

Over one-third of the global population lives within $100 \mathrm{~km}$ of the coast $[1,2]$, and many in these regions depend on the numerous ecosystem services provided by coastal and marine environments, such as food provision, employment, natural disaster mitigation, and water filtration [1,3]. Yet, threats including population growth, land use change, overfishing, pollution, and climate change impair ecosystem functioning through biodiversity loss and habitat fragmentation [4-7]. In response, spatially explicit ocean zoning approaches have gained global recognition as a practical way to organize marine spaces and minimize adverse impacts $[8,9]$. Ecosystem-based coastal and marine spatial planning (MSP) is an integrated approach that assigns spatial and temporal constraints on human activities in marine areas to balance environmental, social, and economic objectives [10]. MSP aims to explicitly assess user-user and user-environment interactions and tradeoffs to maximize the full range of ocean services [11,12]. Despite its widespread use, research exploring the relative value, drivers, and distributions of different forms of MSP in various socio-environmental contexts is much needed and essential to understanding its implications and benefits in achieving sustainable use of marine resources. Here, the spatial distributions of two marine spatial management techniques in Japan are examined, conservation-oriented marine protected areas (MPAs) and production-focused territorial use rights for fisheries (TURFs), in order to identify drivers for their use and better predict and understand future expansion of MSP worldwide.

Setting aside marine and coastal regions as MPAs has become a common MSP approach to achieving conservation and restoration targets. Commonly defined as "any area of the intertidal or subtidal terrain, together with its overlying water and associated flora, fauna, historical and cultural features, which has been reserved by law or other effective means to protect part or all of the enclosed environment" [13], MPAs may range from inaccessible no-take marine reserves to multiple use areas. Successful MPAs can facilitate the conservation of critical species and sensitive habitats, as well as enhance biomass, density, and biodiversity within and around its boundaries [14-17]. The 2010 Convention on Biological Diversity (CBD) set the international goal of implementing "protected areas and other effective area-

\footnotetext{
* Corresponding author at: Biology Department, San Diego State University, San Diego, CA, USA.

E-mail address: keiko.nomuraa@gmail.com (K.J. Nomura).
} 
based conservation measures" on at least $10 \%$ of the world's coastal and marine area by 2020 , with a focus on areas important for biodiversity or ecosystem services [18]; currently, MPAs cover about $4.12 \%$ of all oceans [19]. Global application has rapidly increased over the last decade $[20,21]$, and MPAs are now a major component of marine conservation and management in many places worldwide.

Rights-based fisheries management (RBFM) has become increasingly prominent as a fisheries management tool since overexploitation and resource degradation are often associated with a lack of property rights [22,23]. RBFM presents a potential solution by granting fishers ownership of resources and thereby incentivizing sustainable resource use [24-26]. TURFs are a widely implemented RBFM strategy that allots individuals or communities a geographic area within which they are allowed exclusive access to marine resources [27]. TURF use has been shown to enhance managed species stocks [28], and well-enforced TURFs may act similarly to MPAs by benefitting non-target population growth and overall biodiversity [29-31]. Historical island fishing communities like Fiji and Samoa have long practiced TURF management through customary marine tenure rights [32-34], while other nations have more recently distributed TURF rights to replace open access areas or other forms of management (e.g., Chile transitioned to a large system of coastal TURFs following the collapse of their loco fishery in the late 1980s [28]).

Aside from the fact that both MPAs and TURFs rely on spatially defined controls, the two management approaches differ substantially. Despite multiple uses of many protected areas, MPAs often establish zones of no use and are generally implemented as conservation measures. TURFs, however, are primarily intended for managing important fisheries and marine resources [35]. With the exception of no-access areas, MPAs are public lands, whereas TURFs are rightsbased, private properties only accessible by certain user groups. MPA management is typically top-down with authoritative bodies at the national or state levels (with some notable exceptions; e.g., Alcala and Russ [36]), while TURFs are frequently co-managed by individuals or local fishing communities together with government agencies [35]. Due to these distinctions, the implementation of each likely responds to different sets of socioeconomic and biological conditions. Nevertheless, there have to date been few comparative examinations of MPAs and TURFs in a single spatiotemporal context (see Afflerbach et al. [37] for an exception examining TURF-reserves globally).

Marinesque et al. [38] and Fox et al. [39] examined global MPA distributions and both found little link between potential explanatory factors and number or area of MPAs at the international level. The welldocumented ecological benefits of MPAs [14,40,41] suggest that spatial patterns of establishment should be related to environmental conditions. Depending on context, one might expect MPA implementation to be positively or negatively correlated to ecosystem productivity or services, e.g., by targeting vulnerable, yet productive, marine ecosystems to maximize conservation benefits or by avoiding highly productive areas in order to minimize adverse impacts to fisheries [42-44]. Additionally, given the short-term costs of area closures to fisheries and other maritime sectors, as well as the potential long-term fisheries benefits of MPAs via spillover of larvae or adults to fished areas [45], one might also predict MPA distributions to be linked to socioeconomic factors. Despite these logical associations, global examinations have not observed strong correlations between national MPA distributions and biological or socioeconomic indicators $[38,39]$. These findings may be due to extremely heterogeneous sociopolitical and environmental contexts on a global scale, suggesting regional or national analyses could yield useful insights.

While several studies have examined the relationship between TURF characteristics and their effectiveness for resource management $[35,46]$, relatively less attention has been given to potential explanatory factors underlying TURF implementation and distributions. As a fisheries management tool, the use of TURFs should depend upon the presence of fishers and fisheries resources. Moreover, usage may be a function of the type and extent of marine resource exploitation in an area. Spatially-explicit RBFM techniques are more appropriate for managing low mobility species whose full life cycles are likely to be contained within the tenured boundaries [35,47-49]. It is thus anticipated that TURF distributions are associated with high quantities of sedentary and benthic species, as well as environmental conditions which favor productive benthic communities. TURFs might also be more plentiful in areas with fewer stakeholders competing for marine space. Conflicts between coastal fisheries and other interests like shoreline development, energy production, recreation, and conservation (MPAs) could deter TURF formation [50].

The goal in this study is to identify potential socioeconomic, environmental, and fisheries drivers influencing the distributions of these two MSP techniques within the maritime borders of one particular country - Japan. By working within the framework of a single nation, these regression models aim to identify spatial determinants that may have been obscured by the extreme heterogeneity of national contexts in other global surveys (e.g., Marinesque et al. [38]; Fox et al. [39]). Japan provides an ideal setting for understanding MSP drivers as marine resources play an important role from national to local levels [51-53], and, therefore, one would expect a close link between pertinent explanatory factors and MSP. In addition to hosting extensive TURF networks [35] and committing to MPA expansion under CBD agreements, Japan is subdivided into a set of states (i.e., prefectures) that vary substantially in terms of socioeconomic characteristics and marine ecosystems [52], presenting sufficient contrast to examine subnational differences in MSP use.

The rest of this paper is organized as follows. An overview of the uses of MPAs and TURFs in Japan is provided, followed by descriptions of the geographic, socioeconomic, and biological datasets used in this study. Statistical methods to relate prefecture-level data to the use of MPAs and TURFs are then described before presenting results. The discussion then places the results in the wider context of national and international use of MSP for conservation and fisheries management.

\section{MPAs and TURFs in Japan}

Japan has a coastline of around $29,750 \mathrm{~km}$ and the sixth largest Exclusive Economic Zone (EEZ) in the world. Temperate to tropical climates and distinct ocean currents support a range of coastal and marine ecosystems including salt marshes, mangroves, seaweed beds, rocky shores, and coral reefs. This biodiversity has formed some of the world's richest fishing grounds. Most of the country's land area consists of mountainous terrain which has led to particularly dense coastal populations [52]. As coastal pressures continue to mount, efforts to understand how Japan has allocated marine space with respect to conservation and fishing sectors becomes increasingly important.

Although Japan is participating in the international commitment of achieving $10 \%$ global MPA coverage, the country does not currently have a centralized MPA management system. Several laws, including the Natural Parks Law, Nature Conservation Law, and the Act on the Protection of Fisheries Resources, can establish MPAs with various goals and management types [54]. Supervision lies with the prefectural governments and, depending on the legislation that established the protected area, falls under the auspices of either the Ministry of the Environment (MOE) or the Ministry of Agriculture, Forestry, and Fisheries (MAFF) [54]. Therefore, in contrast to several other nations (e.g., the European Natura 2000 network, the US National MPA Center, and the French Agence d'Aires Marines Protégées), Japan lacks a single administrative body for its collective MPA network. Nevertheless, the Japanese government's 2011 Marine Biodiversity Conservation Strategy aims to increase coordination between the two national ministries responsible for MPAs by establishing guidelines for nationwide MPA network expansion [55]. While the guidelines do provide direction for future growth, only approximately $0.49 \%$, or $19,940 \mathrm{~km}^{2}$, of Japan's EEZ is currently protected [56]. 


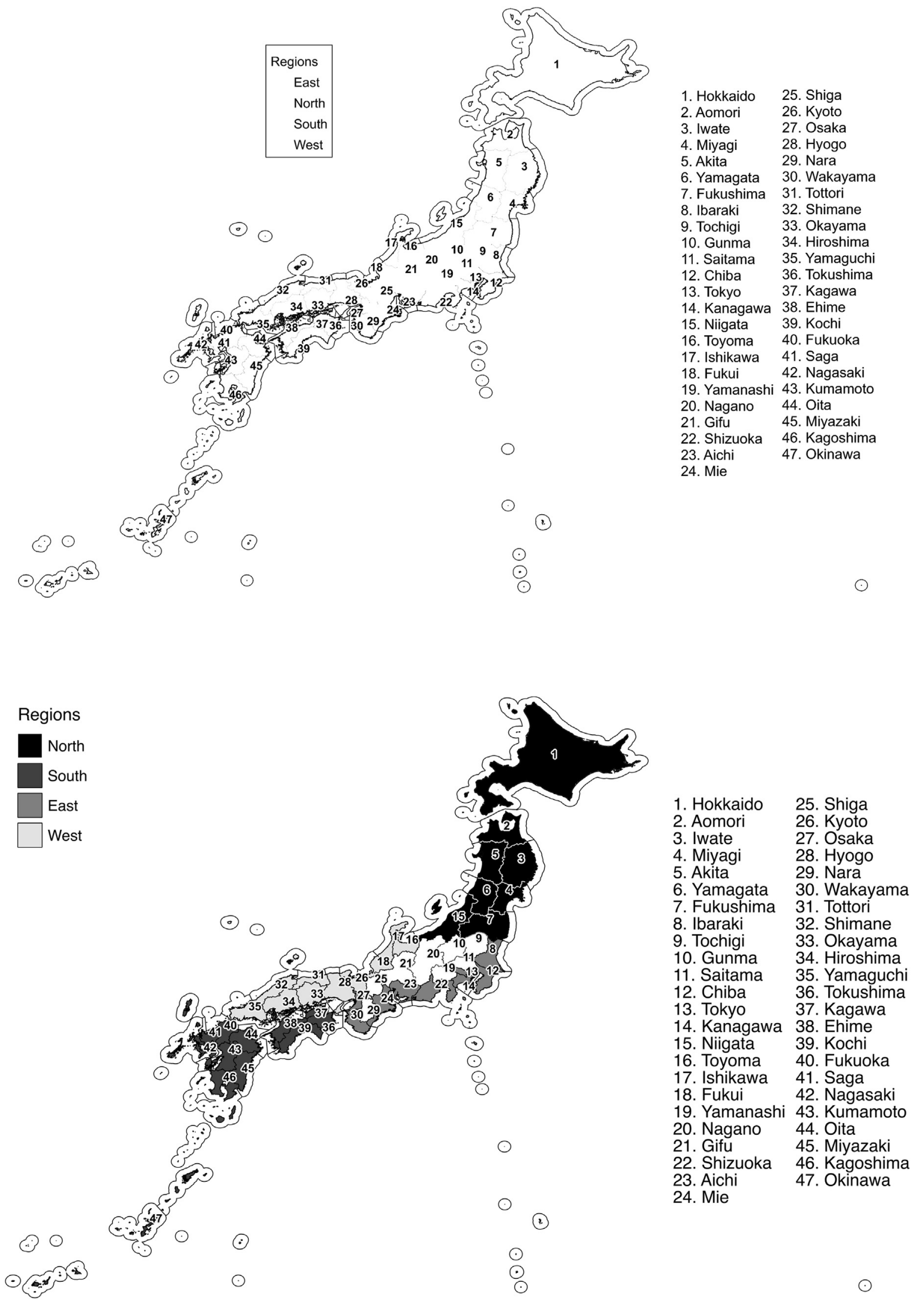

Fig. 1. National distributions of (a) MPAs and (b) FCAs in Japan. 
Japan has one of the world's oldest and most successful marine fisheries co-management regimes [50,57]. For hundreds of years, coastal fisheries were publicly owned and managed by local resource users [50]. Then, during the feudal seventeenth century, coastal villages were given sole property rights of the waters [51]. The Fishery Law of 1949 established the current management system, which operates via a nested structure and allows local communities to maintain considerable control and management authority [51,58]. The MAFF presides at the national level, and sets total allowable catch limits (TACs) for eight particularly important species. Each prefectural government manages its coastal resources and allocates various fishing rights to individuals, groups, and Fishery Cooperative Associations (FCAs). FCAs represent community-level fishing entities that acquire exclusive access rights and authorization to manage fisheries resources [58]. Though FCA-managed areas operate within the nationally set TACs and broad prefectural regulations, they are functionally TURFs in that FCAs have exclusive access and establish their own input controls such as gear type, fishing seasons, and area closures [52]. For species without nationally set TACs, local management is even more autonomous. Fishery Management Organizations (FMOs) are groups of fishers who operate beneath a parent FCA to collectively manage shared fishing grounds and/or targeted species within or between TURFs [51]. Each TURF is managed by a single FCA, but may be affiliated with several FMOs. Although there are notable exceptions [59], Japanese coastal fishing entities (FCAs or FMOs) primarily focus on single-species rather than multispecies or ecosystem-based management [51].

\section{Methods}

\subsection{Data collection}

National distributions of MPAs and TURFs in Japan were analyzed by evaluating prefecture-level counts of each MSP tool. The World Database on Protected Areas (WDPA) provided locational information on Protected Areas in Japan. The national data sheet was filtered to only include MPAs, and any MPA existing within multiple prefecture boundaries was counted once per prefecture. Currently, there is no existing data on the number of TURFs throughout Japan; FCA data collected through Japan's 2008 Fisheries Census Survey was therefore used as a proxy for TURFs since each FCA is assigned a single TURF. The WDPA database also contains the areas of all recorded MPAs. Unfortunately, similar TURF data is not available, and thus a comparison of MPA and TURF extents could not be performed.

Prefecture-level socioeconomic, environmental, and fisheries data were initially acquired from online databases in spreadsheet or GIS format (detailed source data found in Table A.1). NASA and UNEPWCMC global databases provided geospatial environmental information, but most other data were gathered from Japanese databases, including the National Survey on the Natural Environment, the Portal Site of Official Statistics of Japan, the Japan National Land Information Download Service, and the Japan Fisheries Census. Prefectures' marine environments were characterized by the mean, extremes, and standard deviation of physical oceanographic parameters (e.g., sea surface temperature, productivity, bathymetry), as well as by the extent of several important marine habitats (coral reefs, mangroves, seaweed beds, tidal flats, wetlands). The size of the coastal fisher workforce, as well as landings and production data, were used to provide an indication of fisheries presence and resource usage. Metrics such as population density, income per capita, and the numbers of trading and fishing ports were used to quantify potentially important socioeconomic factors. Trading and fishing port designations adhere to definitions contained in the Port and Harbour Law and the Fishing Port Law [60], respectively. Though not mutually exclusive, these two port categories generally denote larger national and international ports with commercial, as well as fishing, traffic versus smaller regional ports primarily devoted to fishing.

\subsection{Data processing}

The acquired spatial data was evaluated using ArcGIS (ESRI version 10.3) to assemble an appropriate database for analysis. Marine characteristics were analyzed within prefectural territorial waters that were established by buffering 12-nautical miles from an administrative shoreline layer depicting Japan's coastline (coastline shapefile from the Database of Global Administrative Areas (GADM) [61]). No Japanese MPAs in the WDPA database were outside of these territorial waters, and FCAs only extend beyond these limits in very rare cases. The national territorial waters were manually cut following prefectural boundaries to create territorial waters for each prefecture (Fig. 1). Accurate boundaries were ensured by referring to CeisNet, a website GIS application managed by the Japanese Coast Guard containing a number of spatial layers aligned with prefecture boundaries [http:// www2.kaiho.mlit.go.jp/]. Ocean productivity, sea surface temperature, and bathymetry layers were summarized in terms of their means, maximums, minimums, and standard deviations for the territorial waters of each prefecture from raster data for each of these oceanographic parameters. A point shapefile of the national distribution of trading ports was also summarized by prefecture. Marine ecoregion areas within the territorial waters of each prefecture were calculated by intersecting the polygon shapefiles depicting habitat extents and prefectural territorial waters, then expressing ecoregion coverage as a percentage of the total territorial maritime area.

Prefectural coastal fisheries landings data were organized by phylum and level of mobility (anadromous, benthic, demersal, pelagic) and then the fraction of the total catch that each group represented was calculated. A Simpson's diversity index (also known as the Herfindahl index [62]) was calculated using these groups to measure landings' diversity. Certain variables were standardized by coastline length (e.g. trading ports is expressed as a quantity per $\mathrm{km}$ of coastline). The initially compiled dataset included 36 predictors.

Cross-correlation analyses were then performed to identify significantly correlated pairs of variables $(r>0.31$, to correspond to $\mathrm{p}<0.05$ ) and several redundant variables were removed (e.g., fishers per $\mathrm{km}$ coastline was kept while fishing ports per $\mathrm{km}$ coastline was discarded; see Fig. A.1 and Table A.2 for cross-correlation results and a full list of redundant variables eliminated). Additionally, to alleviate multicollinearity issues within catch composition data, and since marine TURFs do not exclusively manage anadromous species, the "anadromous fishes" variable was removed. The final dataset contained 21 predictors consisting of three socioeconomic, eight environmental, and ten fisheries variables (Table 1).

Several of the explanatory variables, as well as both MSP techniques, vary considerably among prefectures. Nationwide, FCAs outnumber MPAs 1078 to 270, with prefectures averaging 27.64 FCAs and 6.92 MPAs (Fig. 2). Population densities, calculated using the prefecture's inhabitable area rather than the total area, range from 249 people per $\mathrm{km}^{2}$ on the vast island of Hokkaido to 9207 people per $\mathrm{km}^{2}$ in Tokyo. Marine environments also differ substantially, with coefficients of variation of 1.49 and 0.91 for territorial maritime area and average ocean productivity, respectively. Coral reef and mangrove distributions are limited to the country's southern subtropical regions, whereas numerous wetlands and tidal flats are scattered throughout the coastline [52]; despite being present in all prefectural waters, seaweed coverage still has a coefficient of variation of 0.83 . This array of abiotic factors and resulting ecosystems supports Japan's diverse fishing grounds, which is reflected in highly variable catch data. To uncover any broad geographical differences or trends in MSP use, regional indicator variables were constructed by dividing Japan's prefectures into North, South, East, and West regions (Fig. 1).

\subsection{Statistical analysis}

Generalized linear models (GLMs) were used to evaluate the impacts 
Table 1

Predictor variables and their data sources by category. Landings diversity variable is not included in the table but was calculated using landings data.

\begin{tabular}{|c|c|c|}
\hline Category & Variables & Source \\
\hline \multirow[t]{4}{*}{ Environmental } & Territorial maritime area & Derived from GADM layer in ArcGIS \\
\hline & Mean bathymetry & NASA \\
\hline & Mean annual productivity & UNEP-WCMC \\
\hline & Ecoregions (coral reefs, mangroves, seaweed beds, tidal flats, wetlands) & National Survey on the Natural Environment \\
\hline \multirow[t]{3}{*}{ Socioeconomic } & Population density & Portal Site of Official Statistics of Japan \\
\hline & Income per capita & \\
\hline & Trade ports per $\mathrm{km}$ coastline & $\begin{array}{l}\text { Japan National Land Information Download } \\
\text { Service }\end{array}$ \\
\hline \multirow[t]{2}{*}{ Fisheries } & $\begin{array}{l}\text { Landings (algae, benthic crustaceans, benthic echinoderms, benthic molluscs, cephalopods, demersal fishes, } \\
\text { demersal eels, pelagic fishes) }\end{array}$ & Japan Fisheries Census \\
\hline & Fishers per km coastline & Portal Site of Official Statistics of Japan \\
\hline
\end{tabular}

of socioeconomic, environmental, and fisheries variables on the number of MPAs and FCAs in each prefecture. Relationships between management (i.e., FCA and MPA numbers) and fisheries variables may be endogenous, therefore two separate models explaining MPA and FCA counts were run: one including only socioeconomic and environmental variables, and another which also included fisheries factors. All statistical analyses were performed in the statistical software $R$ [63]. Regression-based tests for overdispersion contained in the package AER [64] were first used to assess model dispersion and determine the most appropriate GLM model structure to use. As overdispersion was found in most of the models, a negative binomial distribution for the residuals of predicted variables was used in all cases. GLMs were executed using functions found within the MASS package [65]. Additionally, to correct for the increase in family-wise Type 1 error rate associated with multiple comparisons [66], p-values for the coefficients of each explanatory factor in the models were adjusted utilizing the DunnSidak correction method $[67,68]$, though both unadjusted and adjusted $\mathrm{p}$-values are reported in the results. Using the package pscl [69], pseudo $\mathrm{R}^{2}$ values were determined for each model to describe the amount of variation in MPA and FCA counts explained by the prefectural data.

\section{Results}

\section{1. $M P A s$}

When fisheries variables are included, environmental and ecoregion variables are significant: percentage seaweed beds and tidal flats have significant positive relationships with MPA counts, while average ocean productivity shows a significant negative relationship (Table 2). How- ever, the coefficients of these predictor variables are no longer significant after correcting p-values for multiple comparisons. Surprisingly, this model has a high pseudo $\mathrm{R}^{2}$ despite there being no significant predictors and having controlled for multicollinearity by eliminating highly correlated covariates. The second model excluding fisheries variables did not reveal any significant predictors at the $\mathrm{p}<0.05$ level with or without correction for multiple comparisons (Table 2).

\subsection{FCAs}

The full FCA model indicates several statistically significant fisheries variables including landings' diversity, fisher density along the coast, and landing compositions of pelagic and demersal fishes, cephalopods, and benthic organisms (Table 3). Maritime area and the density of trading ports are also significant positive predictors. Coefficients for cephalopod and benthic organism landings, as well as landings' diversity, continue to be significant after adjusting p-values for multiple comparisons. All significant predictors in the full model were positively related to FCA counts, except for the landings' Simpson's diversity index.

Several significant ecoregion and environmental parameters emerge as significantly related to FCA counts once fisheries variables are removed (Table 3 ). While coral and wetland coverage are negatively related with FCAs, mangrove coverage shows a positive relationship. Bathymetry is found to be positively related, while average ocean productivity is a strong negative predictor of FCA counts. Territorial maritime area and trading ports per $\mathrm{km}$ of coastline also have significant positive relationships to FCA counts. Regional variables indicated the presence of significantly more FCAs in eastern Japan.
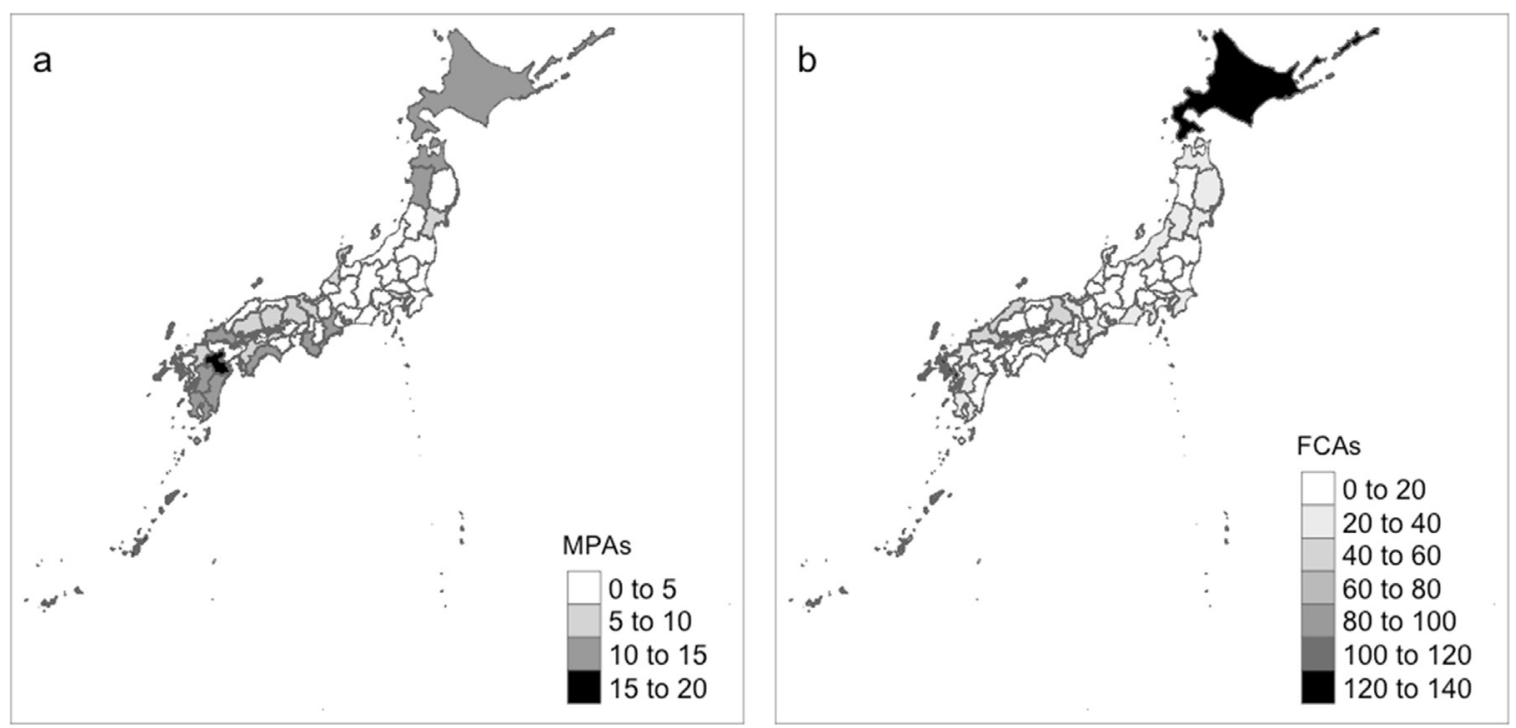

Fig. 2. GIS layer of Japan displaying buffered prefectural territorial waters and four geographic regions. 
Table 2

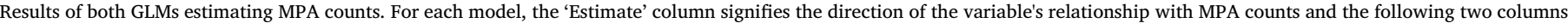

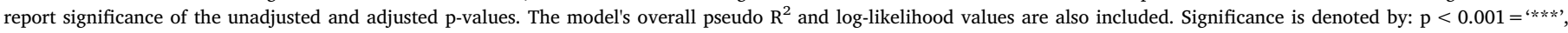
$\mathrm{p}<0.01={ }^{(* *)}, \mathrm{p}<0.05={ }^{(*)}, \mathrm{p}<0.1=$ ‘'

\begin{tabular}{|c|c|c|c|c|c|c|}
\hline \multirow[b]{2}{*}{ Prefectural parameters } & \multicolumn{3}{|c|}{ MPA counts (full model) } & \multicolumn{3}{|c|}{ MPA counts (model without fisheries) } \\
\hline & Estimate & Significance & Adjusted significance & Estimate & Significance & Adjusted significance \\
\hline Maritime area & + & & & + & & \\
\hline Mean bathymetry & + & & & + & & \\
\hline Mean annual productivity & - & * & & - & & \\
\hline Percent coral & + & & & + & . & \\
\hline Percent mangrove & - & & & - & & \\
\hline Percent seaweed & + & * & & + & . & \\
\hline Percent tidal flat & + & * & & + & . & \\
\hline Percent wetland & + & & & - & & \\
\hline Income per capita & - & & & + & & \\
\hline Population density & + & . & & + & & \\
\hline Trade ports per km coastline & - & & & - & & \\
\hline East prefectures & + & & & - & & \\
\hline North prefectures & - & & & + & & \\
\hline West prefectures & + & & & - & & \\
\hline Fishers per km coastline & - & & & & & \\
\hline Algae & - & & & & & \\
\hline Benthic crustaceans & + & & & & & \\
\hline Benthic echinoderms & + & & & & & \\
\hline Benthic molluscs & - & & & & & \\
\hline Cephalopods & + & & & & & \\
\hline Demersal eels & + & & & & & \\
\hline Demersal fishes & - & & & & & \\
\hline Pelagic fishes & - & & & & & \\
\hline Landings Simpson Index & + & & & & & \\
\hline (Cragg \& Uhler) Pseudo $\mathrm{R}^{2}$ & 0.84 & & & 0.40 & & \\
\hline Log-likelihood & -76.38 & & & -100.32 & & \\
\hline
\end{tabular}

Table 3

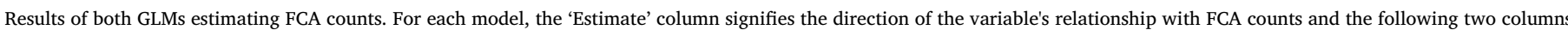

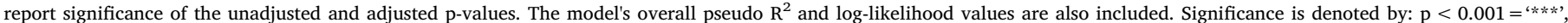
$\mathrm{p}<0.01={ }^{(* *}, \mathrm{p}<0.05={ }^{(*)}, \mathrm{p}<0.1=$ '

\begin{tabular}{|c|c|c|c|c|c|c|}
\hline \multirow[b]{2}{*}{ Prefectural Parameters } & \multicolumn{3}{|c|}{ FCA counts (full model) } & \multicolumn{3}{|c|}{ FCA counts (model without fisheries) } \\
\hline & Estimate & Significance & Adjusted significance & Estimate & Significance & Adjusted significance \\
\hline Maritime area & + & $* *$ & & + & $* * *$ & $* * *$ \\
\hline Mean bathymetry & + & & & + & . & \\
\hline Mean annual productivity & - & & & - & $* * *$ & $* *$ \\
\hline Percent coral & + & & & - & $* * *$ & $* * *$ \\
\hline Percent mangrove & - & & & + & $* * *$ & $* *$ \\
\hline Percent seaweed & - & & & + & & \\
\hline Percent tidal flat & - & & & + & & \\
\hline Percent wetland & - & & & - & * & \\
\hline Income per capita & + & & & - & & \\
\hline Population density & - & & & - & & \\
\hline Trade ports per km coastline & + & $* *$ & & + & * & \\
\hline East prefectures & - & & & + & * & \\
\hline North prefectures & - & & & + & & \\
\hline West prefectures & - & & & + & & \\
\hline Fishers per km coastline & + & * & & & & \\
\hline Algae & + & & & & & \\
\hline Benthic crustaceans & + & $* * *$ & $*$ & & & \\
\hline Benthic echinoderms & + & $* *$ & $*$ & & & \\
\hline Benthic molluscs & + & $* * *$ & $* *$ & & & \\
\hline Cephalopods & + & $* * *$ & $*$ & & & \\
\hline Demersal eels & - & & & & & \\
\hline Demersal fishes & + & $*$ & & & & \\
\hline Pelagic fishes & + & $*$ & & & & \\
\hline Landings Simpson Index & - & $* * *$ & $* * *$ & & & \\
\hline (Cragg \& Uhler) Pseudo $\mathrm{R}^{2}$ & 0.88 & & & 0.66 & & \\
\hline Log-likelihood & -128.47 & & & -146.31 & & \\
\hline
\end{tabular}


After adjusting p-values, only maritime area, average ocean productivity, and coral and mangrove coverage remain significant.

\section{Discussion}

\subsection{Understanding patterns behind MPA use}

Factors influencing the number of MPAs throughout Japan were examined, and although MPA counts were found to be related to a few environmental factors, the relationships were weak and statistical significance disappeared after adjusting p-values for multiple comparisons. This analysis is consistent with global analyses of the distribution of MPAs across countries, which found similarly weak relationships between the number or area of MPAs in a country and potential biological or socioeconomic explanatory factors $[38,39]$. Surprisingly, the driving factors behind implementation of MPAs are no clearer at the finer spatial scale of a single nation.

A number of confounding factors might have obscured relationships between MPA spatial trends and predictor variables. One explanation contends that the inherently political process of MPA creation may undermine the development of ecologically representative or otherwise predictable networks $[70,71]$. As illustrated by rapid increases in largescale MPAs following international agreements [44,72], political motivations to achieve coverage targets may influence interest in expanding marine protection. Such MPAs might be located in remote or already undisturbed marine regions where impacts of area closures to resource users are minimal [44]. Japan's diverse and abundant coastal stakeholders might similarly complicate the establishment process. Proposals and planning discussions are often drawn into power struggles between user groups striving to minimize costs to their own operations, and the resulting MPA network could greatly differ from the one initially proposed [73]. However, it is not immediately clear why stakeholder conflicts would produce ambiguous relationships of predictor variables with MPA networks instead of close relationships between socioeconomic predictors and MPAs.

A single set of drivers for Japan's MPA network may not exist given the broad functionalities encompassed by the term 'MPA.' Objectives can range from biodiversity protection to fisheries rehabilitation, recreational usages, and more. Further, based on their function, Japanese MPAs are governed by separate entities and frequently come to fruition through different processes. MPAs managed by the fisheries agency, MAFF, are intended to protect fisheries resources and are motivated from the bottom-up by coastal stakeholders, while the environmental ministry, MOE, oversees MPAs designed to conserve biodiversity through top-down regulations [54]. As a result, the national network lacks uniformity regarding motives and processes of establishment. Examining the drivers behind MPAs with shared functions and/or management structures might yield stronger relationships to explanatory factors.

Additional ambiguity may arise as official data only describes legally imposed MPAs despite the existence of other legitimate MPA candidates. For example, satoumi are particularly productive and diverse marine extractive areas that Japanese fishers and other resource users actively maintain through conservation activities including critical habitat restoration, invasive species eradication, and water quality improvement [31]. Given their widespread utility for conserving biodiversity, it has been proposed that such areas in Japan be considered in international MPA agreements [31]. Additionally, TURFs with autonomous fishing regulations can, at times, be analogous to legal MPAs intended to restore fisheries resources [28,30]. Future research should focus on acquiring a comprehensive dataset of such unreported or traditionally managed MPAs to better elucidate conservation trends in ocean management.

It is generally assumed that fishers oppose MPA implementation, though this analysis shows no relationship between the amount or type of fishing pressure and the number of MPAs in a prefecture. Japanese fishers might seek to enact self-imposed conservation measures such as fishing regulations and satoumi rather than pursue legal MPAs [50,54]. Further, the strong tenure rights of Japanese coastal fishers prohibit intrusion of legal MPAs onto fishing grounds and likely helps to avoid conflicts between conservation and fisheries sectors. Additionally, fishers' perceptions of MPAs should not be generalized given that areas intended for restoring fisheries resources presumably receive less resistance than those with stricter conservation objectives. Considering Japan's declining fisher population, identifying potential trends between fishers and MPAs will be useful to understand how the country's ocean conservation network might respond to upcoming demographic shifts.

\subsection{Understanding patterns behind TURF use}

The models used here revealed that the Japanese TURF distribution (as proxied by FCAs) is more predictable than that of MPAs. One explanation is that since TURFs are established solely for fisheries production objectives, the reasons prompting their implementation are more consistent than those behind the wide functioning MPA network. National management consolidation of TURFs under the MAFF also offers a more systematic approach to organizing the network compared to the split federal management of MPAs. Further, the responsibility of prefectures to grant fishing rights for TURFs generates subnational decision-making processes from which distinct usage patterns could arise.

In the model without fisheries variables, several environmental covariates were found to be highly significant predictors of FCA (TURF) counts. TURFs are generally more common along less productive coastal zones in Japan, as well as where a smaller fraction of the territorial waters are coral reefs or where a larger fraction are mangroves. These significant environmental effects may arise due to their associated fisheries impacts. In less productive coastal waters of Japan, catches of low mobility benthic species and algae tend to dominate. With respect to habitat coverage, there are fewer fishers and catch in areas with large amounts of coral reefs. Prefectures with a higher density of trading ports were associated with more FCAs, indicating possible integration between the fishing and trading industries. Although increased maritime traffic could potentially disturb nearby fishing grounds and operations, trading ports provide fishers with processing and distribution infrastructure as well as access to nonlocal markets for their harvested products. Such a relationship demonstrates that spatial coordination of certain relatively low conflict sectors might evolve within multiple use marine areas.

A clear positive relationship exists between the number of TURFs in a prefecture and benthic landings (crustaceans, mollusks, echinoderms), supporting the claim that TURFs are more suitable for managing less mobile species. Similarly, cephalopod landings are positively associated with TURFs likely because relatively non-mobile, highly valued octopus species dominate this catch category. Additionally, as coastal fishing entities frequently focus on harvesting individual species, prefectures that recorded more diverse catch compositions had more TURFs. Japan's diverse fishing grounds may allow for differentiated resource extraction, minimizing competition and promoting the formation of numerous specialized TURFs.

\section{Conclusion}

MSP networks are emerging worldwide as an organizational tool for sustainably managing multiple use marine environments. While monitoring global progress is undoubtedly critical, the processes underlying MSP implementation likely occur at much smaller scales. Here, the distributions of MPAs and TURFs across prefectures throughout Japan were examined. Predictive models confirmed that TURFs are related to economic and fisheries factors, but attempts to capture drivers of MPA use remained largely inconclusive. Japan's clear socioeconomic depen- 
dency on TURFs for coastal fisheries production, combined with a coherent national management system, likely allowed common characteristics to emerge in their distributions. Conversely, one MPA network may encompass several diverse objectives and functionalities that result from many separate and often competing factors. The disjointed management of Japanese MPAs according to function may further mask variables influencing MPA network expansion. More insightful results might surface if analyses were restricted to a narrowly defined set of spatial management controls commonly used in MPAs (e.g., no take areas), or by only evaluating MPAs managed by a single government agency (e.g., the MOE in Japan). A comprehensive analysis including autonomous conservation management like satoumi or coordinated area closures could also elucidate stronger spatial trends in marine conservation. Detailed understanding of the processes transforming marine management is essential to predict responses of MSP networks to dynamic biological and socioeconomic environments.

\section{Acknowledgements}

Keiko Nomura sincerely thanks Hiro Uchida and Hiroki Wakamatsu for relaying information about Japanese management via personal communication and an anonymous reviewer for constructive criticisms on preliminary versions of the paper. This work was supported by the VIMS Research Experience for Undergraduates and was made available through a Grant awarded from the National Science Foundation (grant \# NSF OCE 1062882) to Linda Schaffner and Rochelle Seitz. Keiko Nomura also thanks Jenny Dreyer and Melissa Karp for coordinating the REU program at the Virginia Institute of Marine Science. This is contribution No. 3631 of the Virginia Institute of Marine Science, College of William and Mary.

\section{Appendix A. Supporting information}

Supplementary data associated with this article can be found in the online version at http://dx.doi.org/10.1016/j.marpol.2017.05.005.

\section{References}

[1] C. Brown, E. Corcoran, P. Herkenrath, J. Thonell, Marine and Coastal Ecosystems and Human Well-being: A Synthesis Report Based on the Findings of the Millennium Ecosystem Assessment, 2006.

[2] C. Small, R.J. Nicholls, A global analysis of human settlement in coastal zones, J. Coast. Res. 19 (2003) 584-599.

[3] The State of the World Fisheries and Aquaculture: Opportunities and Challenges, 2014. 〈http://www.fao.org/3/a-i3720e.pdf 〉.

[4] C. Kremen, Managing ecosystem services: what do we need to know about their ecology? Ecol. Lett. 8 (2005) 468-479, http://dx.doi.org/10.1111/j.1461-0248. 2005.00751.x

[5] B. Worm, E.B. Barbier, N. Beaumont, E.J. Duffy, C. Folke, B.S. Halpern, J.B.C. Jackson, H.K. Lotze, M. Fiorenza, S.R. Palumbi, E. Sala, K. A. Selkoe, J.J. Stachowicz, R. Watson, Impacts of biodiversity loss on ocean ecosystem services, Science 314 (2006) 787-790.

[6] S.R. Cooley, H.L. Kite-Powell, S.C. Doney, Ocean acidification's potential to alter global marine ecosystem services, Oceanography 22 (2009) 172-181, http://dx.doi. org/10.5670/oceanog.2009.106.

[7] N.M. Haddad, L.A. Brudvig, J. Clobert, K.F. Davies, A. Gonzalez, R.D. Holt, T.E. Lovejoy, J.O. Sexton, M.P. Austin, C.D. Collins, W.M. Cook, E.I. Damschen, R.M. Ewers, B.L. Foster, C.N. Jenkins, A.J. King, W.F. Laurance, D.J. Levey, C.R. Margules, B.A. Melbourne, A.O. Nicholls, J.L. Orrock, D.-X. Song, J.R. Townshend, Habitat fragmentation and its lasting impact on Earth's ecosystems, Sci. Adv. 1 (2015) e1500052, http://dx.doi.org/10.1126/sciadv.1500052.

[8] F. Douvere, The importance of marine spatial planning in advancing ecosystembased sea use management, Mar. Policy 32 (2008) 762-771, http://dx.doi.org/10. 1016/j.marpol.2008.03.021.

[9] B.S. Halpern, J. Diamond, S. Gaines, S. Gelcich, M. Gleason, S. Jennings, S. Lester, A. Mace, L. McCook, K. McLeod, N. Napoli, K. Rawson, J. Rice, A. Rosenberg, M. Ruckelshaus, B. Saier, P. Sandifer, S. Astrid, A. Zivian, Near-term priorities for the science, policy and practice of Coastal and Marine Spatial Planning (CMSP), Mar. Policy 36 (2012) 198-205, http://dx.doi.org/10.1016/j.marpol.2011.05.004.

[10] C.N. Ehler, F. Douvere, Marine spatial planning: a step-by-step approach toward ecosystem-based management, Intergov. Oceanogr. Comm. Man Biosphere Program. (2009).

[11] S.E. Lester, C. Costello, B.S. Halpern, S.D. Gaines, C. White, J.A. Barth, Evaluating tradeoffs among ecosystem services to inform marine spatial planning, Mar. Policy
38 (2013) 80-89, http://dx.doi.org/10.1016/j.marpol.2012.05.022.

[12] C. White, B.S. Halpern, C. Vappel, Ecosystem service tradeoff analysis reveals the value of marine spatial planning for multiple ocean uses, Proc. Natl. Acad. Sci. 109 (2012) 4696-4701, http://dx.doi.org/10.1073/pnas.1114215109.

[13] G. Kelleher, A global representative system of marine protected areas, Ocean Coast. Manag. 32 (1996) 123-126, http://dx.doi.org/10.1016/s0964-5691(96)00070-1.

[14] B.S. Halpern, R.R. Warner, Marine reserves have rapid and lasting effects, Ecol. Lett. 5 (2002) 361-366.

[15] G.R. Russ, A.C. Alcala, Do marine reserves export adult fish biomass? Evidence from Apo Island, central Philippines, Mar. Ecol. Prog. Ser. 132 (1996) 1-9, http://dx.doi. org $/ 10.3354 /$ meps132001.

[16] D.H. Williamson, G.R. Russ, A.M. Ayling, No-take marine reserves increase abundance and biomass of reef fish on inshore fringing reefs of the Great Barrier Reef, Environ. Conserv. 31 (2004) 149-159, http://dx.doi.org/10.1017/ S0376892904001262.

[17] H.B. Harrison, D.H. Williamson, R.D. Evans, G.R. Almany, S.R. Thorrold, G.R. Russ, K.A. Feldheim, L. van Herwerden, S. Planes, M. Srinivasan, M.L. Berumen, G.P. Jones, Larval export from marine reserves and the recruitment benefit for fish and fisheries, Curr. Biol. 22 (2012) 1023-1028, http://dx.doi.org/10.1016/j.cub. 2012.04.008.

[18] Aichi Biodiversity Targets, Conv. Biol. Divers. (n.d.). 〈https://www.cbd.int/sp/ targets/> (Accessed 14 April 2016).

[19] UNEP-WCMC, IUCN, Protected Planet Report 2016, Cambridge UK and Gland, Switzerland, 2016.

[20] L.J. Wood, L. Fish, J. Laughren, D. Pauly, Assessing progress towards global marine protection targets: shortfalls in information and action, Oryx 42 (2008) 340-351, http://dx.doi.org/10.1017/S003060530800046X.

[21] L. Boonzaier, D. Pauly, Marine protection targets: an updated assessment of global progress, Oryx 50 (2016) 27-35, http://dx.doi.org/10.1017/S0030605315000848.

[22] H.S. Gordon, The economic theory of a common-property resource: the fishery, J. Polit. Econ. 62 (1954) 124-142.

[23] G. Hardin, The tragedy of the commons, Science 162 (1968) 1243-1248, http://dx. doi.org/10.1126/science.162.3859.1243.

[24] R. Hilborn, J.L. Orensanz, A.M. Parma, Institutions, incentives and the future of fisheries, Philos. Trans. R. Soc. Lond. B Biol. Sci. 360 (2005) 47-57.

[25] R.Q. Grafton, R. Arnason, T. Bjørndal, D. Campbell, H.F. Campbell, C.W. Clark, R. Connor, D.P. Dupont, R. Hannesson, R. Hilborn, Incentive-based approaches to sustainable fisheries, Can. J. Fish. Aquat. Sci. 63 (2006) 699-710.

[26] C. Costello, S. Gaines, J. Lynham, Can catch shares prevent fisheries collapse? Science 321 (2008) 1678-1681.

[27] F.T. Christy, Territorial Use Rights in Marine Fisheries: Definitions and Conditions, UN Food \& Agriculture Organisation, 1982.

[28] S. Gelcich, N. Godoy, L. Prado, J.C. Castilla, Add-on conservation benefits of marine territorial user rights fishery policies in central Chile, Ecol. Appl. 18 (2008) 273-281.

[29] C.Y. Bartlett, C. Manua, J. Cinner, S. Sutton, R. Jimmy, R. South, J. Nilsson, J. Raina, Comparison of outcomes of permanently closed and periodically harvested coral reef reserves, Conserv. Biol. 23 (2009) 1475-1484.

[30] S. Gelcich, M. Fernández, N. Godoy, A. Canepa, L. Prado, J.C. Castilla, Territorial user rights for fisheries as ancillary instruments for marine coastal conservation in Chile, Conserv. Biol. 26 (2012) 1005-1015, http://dx.doi.org/10.1111/j.15231739.2012.01928.x

[31] J. Berque, O. Matsuda, Coastal biodiversity management in Japanese satoumi, Mar. Policy 39 (2013) 191-200.

[32] K. Ruddle, Administration and Conflict Managment in Japanese Coastal Fisheries, FAO, 1992, 〈http://www.fao.org/docrep/003/T0510E/T0510E00.HTM〉 (Accessed 10 June 2015).

[33] R.E. Johannes, The renaissance of community-based marine resource management in Oceania, Annu. Rev. Ecol. Syst. 33 (2002) 317-340, http://dx.doi.org/10.1146/ annurev.ecolsys.33.010802.150524.

[34] K. Lobe, F. Berkes, The padu system of community-based fisheries management: change and local institutional innovation in south India, Mar. Policy 28 (2004) 271-281, http://dx.doi.org/10.1016/S0308-597X(03)00087-3.

[35] G. Auriemma, K. Byler, K. Peterson, A. Yurkanin, C. Costello, DiscoverTURFs: a global assessment of territorial use rights in fisheries to determine variability in success and design, Bren Sch. Environ. Sci. Manag. (2014), 〈http://www.bren.ucsb. edu/research/2014group_projects/documents/discoverturfs_report_final_unsigned. pdf $>$.

[36] A.C. Alcala, G.R. Russ, No-take marine reserves and reef fisheries management in the Philippines: a new people power revolution, J. Hum. Environ. 35 (2006) 245-254, http://dx.doi.org/10.1579/05-A-054R1.1.

[37] J.C. Afflerbach, S.E. Lester, D.T. Dougherty, S.E. Poon, A global survey of "TURFreserves", territorial use rights for fisheries coupled with marine reserves, Glob. Ecol. Conserv. 2 (2014) 97-106, http://dx.doi.org/10.1016/j.gecco.2014.08.001.

[38] S. Marinesque, D.M. Kaplan, L.D. Rodwell, Global implementation of marine protected areas: is the developing world being left behind? Mar. Policy 36 (2012) 727-737, http://dx.doi.org/10.1016/j.marpol.2011.10.010.

[39] H.E. Fox, C.S. Soltanoff, M.B. Mascia, K.M. Haisfield, A.V. Lombana, C.R. Pyke, L. Wood, Explaining global patterns and trends in marine protected area (MPA) development, Mar. Policy 36 (2012) 1131-1138, http://dx.doi.org/10.1016/j. marpol.2012.02.007.

[40] S.E. Lester, B.S. Halpern, K. Grorud-Colvert, J. Lubchenco, B.I. Ruttenberg, S.D. Gaines, S. Airamé, R.R. Warner, Biological effects within no-take marine reserves: a global synthesis, Mar. Ecol. Prog. Ser. 384 (2009) 33-46, http://dx.doi. org/10.3354/meps08029.

[41] G.R. Russ, A.C. Alcala, Marine reserves: long-term protection is required for full 
recovery of predatory fish populations, Oecologia 138 (2004) 622-627, http://dx. doi.org/10.1007/s00442-003-1456-4.

[42] N.C. Ban, N.J. Bax, K.M. Gjerde, R. Devillers, D.C. Dunn, P.K. Dunstan, A.J. Hobday, S.M. Maxwell, D.M. Kaplan, R.L. Pressey, J.A. Ardron, E.T. Game, P.N. Halpin, Systematic conservation planning: a better recipe for managing the high seas for biodiversity conservation and sustainable use, Conserv. Lett. 7 (2014) 41-54, http://dx.doi.org/10.1111/conl.12010.

[43] L.J. McCook, T. Ayling, M.J. Cappo, H. Choat, R.D. Evans, D.M. De Freitas, M. Heupel, T.P. Hughes, G.P. Jones, B. Mapstone, H. Marsh, M. Mills, F.J. Molloy, C.R. Pitcher, R.L. Pressey, G.R. Russ, S. Sutton, H. Sweatman, R. Tobin,

D.R. Wachenfeld, D.H. Williamson, S.D. Gaines, Adaptive management of the Great Barrier Reef: a globally significant demonstration of the benefits of networks of marine reserves, Proc. Natl. Acad. Sci. USA 107 (2010) 18278-18285, http://dx. doi.org/10.1073/pnas.0909335107.

[44] R. Devillers, R.L. Pressey, A. Grech, J.N. Kittinger, G.J. Edgar, T. Ward, R. Watson, Reinventing residual reserves in the sea: are we favouring ease of establishment over need for protection? Aquat. Conserv. Mar. Freshw. Ecosyst. 25 (2014) 480-504, http://dx.doi.org/10.1002/aqc. 2445.

[45] A. Grüss, D.M. Kaplan, S. Guénette, C.M. Roberts, L.W. Botsford, Consequences of adult and juvenile movement for marine protected areas, Biol. Conserv. 144 (2011) 692-702, http://dx.doi.org/10.1016/j.biocon.2010.12.015.

[46] G.L. Gallardo Fernández, W. Stotz, J. Aburto, C. Mondaca, K. Vera, Emerging commons within artisanal fisheries. The Chilean territorial use rights in fisheries (TURFs) within a broader coastal landscape, Int. J. Commons 5 (2011) 459-484, http://dx.doi.org/10.18352/ijc.281.

[47] J.C. Castilla, O. Defeo, Sacrificing dialogue for politics? Science 309 (2005) 2003-2005.

[48] C. White, C. Costello, Matching spatial property rights fisheries with scales of fish dispersal, Ecol. Appl. 21 (2011) 350-362, http://dx.doi.org/10.1890/09-1188.1.

[49] S.E. Poon, K. Bonzon, TURFs Catch Share Design Manual, vol. 3, 2013.

[50] H. Matsuda, M. Makino, M. Tomiyama, S. Gelcich, J.C. Castilla, Fishery management in Japan, Ecol. Res. 25 (2010) 899-907, http://dx.doi.org/10.1007/s11284010-0748-5.

[51] H. Uchida, M. Makino, Japanese Coastal Fishery Co-management: an Overview, Case Studies in Fisheries Self-Governance, FAO, Rome, 2008, p. 2015 〈http://www. researchgate.net/publication/23506176_Fishery_Co-Management_in_Japanese_ Coastal_Fisheries> (Accessed 11 June).

[52] I. Popescu, T. Ogushi, Directorate General for Internal Policies Policy Department B: Structural and Cohesion Policies of Fisheries in Japan, (2013). 〈http://www. europarl.europa.eu/RegData/etudes/note/join/2014/529044/IPOL-PECH_ NT(2014)529044_EN.pdf>.

[53] S. Msangi, M. Kobayashi, M. Batka, M. Vannuccini, M. Dey, J. Anderson, Fish to 2030: Prospects for Fisheries and Aquaculture, World Bank, 2014.

[54] N. Yagi, A.P. Takagi, Y. Takada, H. Kurokura, Marine protected areas in Japan: institutional background and management framework, Mar. Policy 34 (2010) 1300-1306, http://dx.doi.org/10.1016/j.marpol.2010.06.001.

[55] Marine Biodiversity Conservation Strategy, Ministry of the Environment, Tokyo,
Japan, 2011.

[56] UNEP-WCMC, Prot. Area Ctry. Profile Jpn. World Database Prot. Areas, 2016. $\langle$ 〈www.protectedplanet.net〉.

[57] R.S. Pomeroy, F. Berkes, Two to tango: the role of government in fisheries comanagement, Mar. Policy 21 (1997) 465-480.

[58] K. McIlwain, N. Smith, Catch Shares in Action: Japanese Common Fishing Rights System, 2013.

[59] Makino, et al, Expanding Fisheries Co-management to Ecosystem-based Management: A Case in the Shiretoko World Natural Heritage area, Japan, (n.d.). 〈http://www.sciencedirect.com/science/article/pii/S0308597×08001012〉 (Accessed 10 June 2015).

[60] Japan Coast Guard Laws and Regulations, (n.d.). 〈http://www.odinwestpac.org/ doc/law/05.pdf> (Accessed 14 April 2017).

[61] Global Administrative Areas, GADM Database Glob. Adm. Areas Version 28., 2016. 〈www.gadm.org〉.

[62] S.A. Rhoades, The Herfindahl-Hirschman index, Fed. Reserve Bull. 79 (1993) 188-189.

[63] R. Core Team, R: A Language and Environment for Statistical Computing, R Foundation for Statistical Computing, Vienna, Austria, 2015〈https://www.Rproject.org/ $>$.

[64] C. Kleiber, A. Zeileis, Applied Econometrics with R, Springer New York, New York, NY, 2008〈http://link.springer.com/10.1007/978-0-387-77318-6〉 (Accessed 19 August 2016).

[65] W.N. Venables, B.D. Ripley, Modern Applied Statistics with S, 4th ed., Springer New York, New York, NY, 2002〈http://www.stats.ox.ac.uk/pub/MASS4〉.

[66] J. Hsu, Multiple Comparisons: Theory and Methods, CRC Press, 1996

[67] H.K. Ury, Comparison of four procedures for multiple comparisons among means (Pairwise contrasts) for arbitrary sample sizes, Technometrics 18 (1976) 89-97, http://dx.doi.org/10.2307/1267921.

[68] T. Hothorn, F. Bretz, P. Westfall, Simultaneous inference in general parametric models, Biom. J. 50 (2008) 346-363, http://dx.doi.org/10.1002/bimj.200810425.

[69] S. Jackman, pscl: Classes and Methods for R Developed in the Political Science Computational Laboratory, Stanford University, Department of Political Science, Stanford University, Stanford, California, 2015〈http://pscl.stanford.edu/ $\rangle$.

[70] T. Agardy, J. Claudet, J.C. Day, "Dangerous Targets" revisited: old dangers in new contexts plague marine protected areas: dangerous targets revisited, Aquat. Conserv. Mar. Freshw. Ecosyst. 26 (2016) 7-23, http://dx.doi.org/10.1002/aqc. 2675.

[71] P. Leenhardt, B. Cazalet, B. Salvat, J. Claudet, F. Feral, The rise of large-scale marine protected areas: conservation or geopolitics? Ocean Coast. Manag. 85 (2013) 112-118, http://dx.doi.org/10.1016/j.ocecoaman.2013.08.013.

[72] E.M. De Santo, P.J.S. Jones, A.M.M. Miller, Fortress conservation at sea: commentary on the Chagos marine protected area, Mar. Policy 35 (2011) 258-260, http://dx.doi.org/10.1016/j.marpol.2010.09.004.

[73] R. Chuenpagdee, J.J. Pascual-Fernández, E. Szeliánszky, J.L. Algeret, J. Fraga, S. Jentoft, Marine protected areas: re-thinking their inception, Mar. Policy 39 (2013) 234-240, http://dx.doi.org/10.1016/j.marpol.2012.10.016. 